\title{
Characterization of Phases Formed Between U-Pu-X Fuels and Fe-Based Cladding
}

\author{
Assel Aitkaliyeva, Brandon D. Miller, James W. Madden, T. P. O’Holleran, J. Rory Kennedy
}

Idaho National Laboratory, Idaho Falls, USA

Uranium-plutonium-zirconium (U-Pu-Zr) and uranium-plutonium-molybdenum (U-Pu-Mo) fuels, known for their high burnup and good thermal response, have been considered as candidate fuels for advanced fast reactors. During their lifetime in the reactor, irradiation in combination with high temperatures can result in swelling of the fuel and its interaction with the cladding. As a result of the complex fuel-cladding chemical interaction (FCCI), integrity of fuel and cladding could be compromised and therefore should be comprehensively examined. As part of the fuel cycle research and development (FCRD) program, formation of intermetallic phases within fuel-cladding interaction zones was investigated in scanning electron microscope (SEM) and transmission electron microscope (TEM).

The diffusion couples were assembled from $\mathrm{U}-\mathrm{Pu}-\mathrm{X}(\mathrm{Mo} / \mathrm{Zr})$ fuel ingots and $\mathrm{Fe}$ and $\mathrm{Fe}-12 \mathrm{Cr}$ cladding. Prior to assembling, the surface of fuel slugs and cladding were polished to mirror polish. Each fuel slug was placed in contact with the cladding material and compressed in a jig, lined with tantalum foil on the inside to prevent an unwanted reaction between diffusion couples and the holder. After assembling, diffusion couples were placed in a furnace and annealed at $700^{\circ} \mathrm{C}$ for 75 hours under continuous flow of argon. Immediately after annealing the jig was quenched in water to preserve the phases formed upon heat treatment.

Diffusion couples were examined using scanning/transmission electron microscopy (STEM/TEM), selected area diffraction (SAD), and X-ray energy dispersive spectroscopy (XEDS) techniques. Cross-sectional specimens were prepared in dual beam focused ion beam (FIB)/scanning electron microscope using a lift-out approach. Prior to TEM specimen preparation, the surface of diffusion couples was examined with energy and wavelength dispersive spectroscopy (WDS) techniques in scanning electron microscope to determine the exact location of the formed interaction layer and to examine resulting microstructure and intermetallic phases.

The heat treatment at $700^{\circ} \mathrm{C}$ resulted in formation of hundreds of microns long reaction zones into the cladding alloy in both Mo and $\mathrm{Zr}$ alloys. Figure 1 shows backscattering electron (BSE) micrograph of the reaction zone formed between Mo alloy and Fe-12Cr cladding material. As a result of interaction, several distinct phases progressing away from the fuel-cladding interface were formed. Multiple lamellas, containing features corresponding to different phases, within reaction zone were prepared to ensure a thorough and accurate identification of intermetallic phases formed in the alloy. Approximate lift-out locations are identified by blue rectangles in Fig. 1.

Figure 2 shows BSE micrograph of the reaction zone formed between Zr alloy and cladding. Similarly to Mo alloy, several distinct phases progressing away from the fuel-cladding interface were formed in $\mathrm{Zr}$ alloy. As opposed to the case of Fe cladding, development of a protective $\mathrm{Zr}$ barrier layer on the fuel surface during heat treatment was not observed with Fe-12Cr cladding. As in case of Mo alloy multiple lamellas, containing all phases formed during high temperature exposure, within reaction zone were prepared to accurately identify intermetallic phases formed in the $\mathrm{Zr}$ alloy. 
Following FIB-based preparation, all specimens were examined in TEM, equipped with energy dispersive spectrometer (EDS). Neither FIB-based specimen preparation nor TEM examination of fresh fuels containing $\mathrm{Pu}$ has been previously published by other research groups. The observed simpler phases in Mo alloy were identified based on the Fe-Cr-O, U-Fe-Cr, and Cr-Mo-O ternary subsystems, and in $\mathrm{Zr}$ alloy using $\mathrm{Fe}-\mathrm{Cr}-\mathrm{O}, \mathrm{U}-\mathrm{Fe}-\mathrm{Cr}, \mathrm{Zr}-\mathrm{Cr}-\mathrm{Fe}$, and $\mathrm{Zr}-\mathrm{Fe}-\mathrm{O}$ ternary subsystems. In this paper the challenges associated with identification of complex systems containing four and more elements, as well as Pu-based quaternary compounds will be discussed and solutions identified. Rapid oxidation of intermetallic phases, Pu-based compounds in particular, will be addressed.

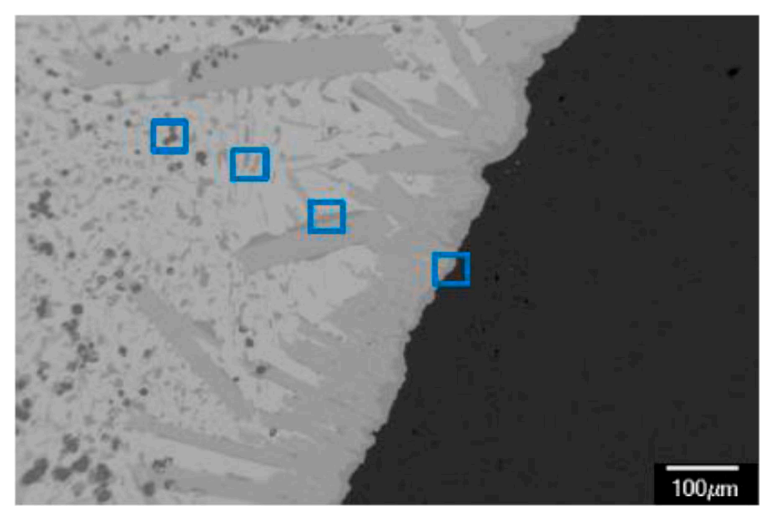

FIG. 1. BSE micrograph of the reaction zone formed between U-TRU-Mo alloy and Fe-12Cr clad after annealing at $700^{\circ} \mathrm{C}$ for 75 hours. Approximate location of each lift-out is identified by blue rectangular box in the micrograph.

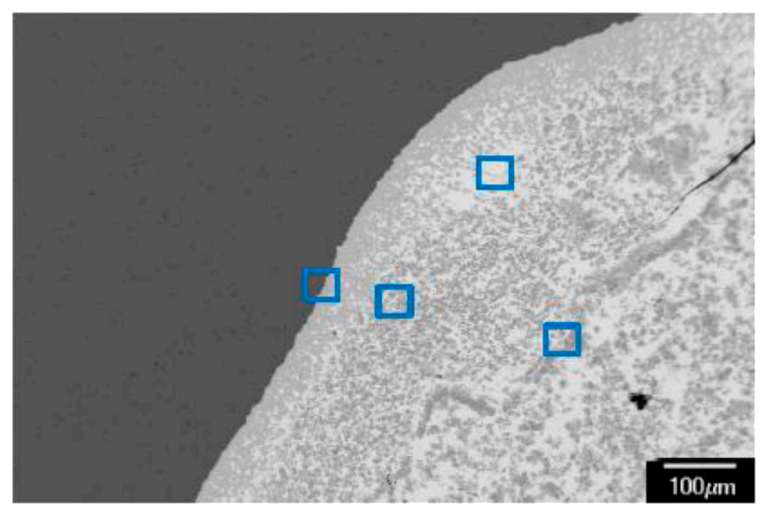

FIG. 2. BSE micrograph of the reaction zone formed between U-TRU-Zr alloy and Fe-12Cr clad after annealing at $700^{\circ} \mathrm{C}$ for 75 hours. Approximate location of each lift-out is identified by blue rectangular box in the micrograph. 